\title{
Experimental Novel Silane System in Adhesion Promotion between Dental Resin and Pretreated Titanium. Part II: Effect of Long-Term Water Storage
}

\author{
Rapid Communication
}

\author{
Jukka P. Matinlinna • Lippo V. Lassila
}

Received: 19 March 2010 / Accepted: 26 April 2010/Published online: 3 June 2010

(C) The Author(s) 2010. This article is published with open access at Springerlink.com

\begin{abstract}
In this study we have assessed the effect of longterm water storage at $37^{\circ} \mathrm{C}$ on silane-aided adhesion promotion. Five experimental silane blends were evaluated as adhesion-promoters. First, five functional organosilane monomers (silicon esters), 3-acryloxypropyltrimethoxysilane, 3methacryloxypropyltrimethoxysilane, 3-glycidoxypropyltrimethoxysilane, tetrakis-(2-methacryloxyethoxy)silane and bis-[3-(triethoxysilyl)propyl]tetrasulfide, were diluted to $1 \%$ $(\mathrm{v} / \mathrm{v})$ in $95 \%$ ethanol and blended with a non-functional crosslinking silane, bis-1,2-(triethoxysilyl)ethane (1\%). A commercially available pre-activated silane product was used as the control. After activation by hydrolysis, each primer blend was applied to silica-coated Ti coupons. Stubs of experimental bisphenol-A-diglycidyldimethacrylate (bis-GMA)-based resin were bonded by photo-polymerization onto the pretreated $\mathrm{Ti}$ coupons. Half of the specimens were stored in deionized water for 6 months and half for 12 months. The primer containing 3acryloxypropyltrimethoxysilane and bis-1,2-(triethoxysilyl) ethane produced significantly higher shear bond strengths than the control silane and other experimental silane primers after both periods of storage.
\end{abstract}

J. P. Matinlinna $(\square)$

Dental Materials Science, Faculty of Dentistry,

The University of Hong Kong,

The Prince Philip Dental Hospital,

34 Hospital Road,

Hong Kong, SAR, People's Republic of China

e-mail: jpmat@hku.hk

L. V. Lassila

Department of Biomaterials Science, Institute of Dentistry,

The University of Turku,

Lemminkäisenkatu 2,

FI-20520 Turku, Finland
Keywords Silica-coating · Silica $\cdot$ Silane coupling agent . Silane monomer $\cdot$ Titanium $\cdot$ Water-storage

\section{Introduction}

Prosthetic metal and alloy constructions such as substructures for dental bridges and crowns are conventionally pretreated by silica-coating and silanization before veneering or cementation $[1,2]$. The promotion of adhesion between dissimilar materials, such as inorganic materials to organic polymers, is carried out with silane coupling agents. They are silicon esters of the type $-\mathrm{Si}(\mathrm{OR})_{3}$ that are synthetic compounds with one or more direct $\equiv \mathrm{Si}-\mathrm{C} \equiv$ bonds [3]. Silanization is usually performed with 3methacryloxypropyltrimethoxysilane in dental laboratories, such as for silica-coated restorations in prosthetic dentistry $[1,2]$. Hydrophobic silane monomers first need to be hydrolyzed, usually with acids, but the hydrolytic stability [4] during long-term wet storage of materials that have been bonded with the aid of silanes is an ongoing concern in dentistry.

Blends of organofunctional silane monomers and crosslinking silanes have made it possible for many resincomposites to achieve considerable hydrolytic stability and mechanical strength. The cross-linking silane is usually non-functional (Fig. 1). For example, bis-1,2-(triethoxysilyl)ethane, which is a so-called bis-functional silane, possesses only hydrolyzable ethoxy groups attached to its two Si atoms. This cross-linking silane is often combined at a 1:5-1:10 ratio with a functional silane monomer $[5,6]$. The thickness of the cross-linked siloxane film that forms on the silica-coated substrate strongly depends on the silane concentration [3, 4]. It is widely accepted that an inter- 
Fig. 1 Silane coupling agent monomers used in the experimental primers : a) 3acryloxypropyltrimethoxysilane (ACPS), b) 3-methacryloxypropyltrimethoxysilane (MPS), c) 3-glycidoxypropyltrimethoxysilane (GPS), d) tetrakis-(2methacryloxyethoxy)silane (TEXS), e) bis-[3-(triethoxysilyl)propyl]tetrasulfide (TSEF), f) bis-1,2- (triethoxysilyl)ethane (BTSE)<smiles>C=CC(=O)OCCC[Si](OC)(OC)OC</smiles>

a)

b)<smiles>C=C(C)C(=O)OCCC[Si](OC)(OC)OC</smiles><smiles>C=C(C)C(=O)OCCO[Si](OCCOC(=O)C(=C)C)(OCCOC(=O)C(=C)C)OCCOC(=O)C(=C)C</smiles>

d)<smiles>CCO[Si](CC[Si](OCC)(OCC)OCC)(OCC)OCC</smiles>

f) penetrating polymer network [7] forms over the functional silane (Fig. 2).

In this study we have evaluated the effect of long-term water storage on novel silane primer systems that are based on bis1,2-(triethoxysilyl)ethane blended with one of five functional silane monomers (Fig. 1): 3-acryloxypropyltrimethoxysilane [8], 3-methacryloxypropyltrimethoxysilane [9], 3glycidoxypropyltrimethoxysilane, tetrakis-(2-methacryloxyethoxy)silane and bis-[3-(triethoxysilyl)propyl]tetrasulfide. A non-filled resin system based on the experimental resin bisphenol-A-diglycidyldimethacrylate (bis-GMA) was used in the shear bond strength assay and examination of failure mode [10]. Ti was used as the substrate because it is the biomaterial of choice for crown implants and bridge substructures and its bonding properties have been widely studied [11-13]. Our hypothesis was that long-term water storage of bonded resin-Ti may weaken the bonding (i.e. shear bond strength) mediated by any of the five experimental functional silane primers.

\section{Experimental}

The materials used in this study are listed elsewhere [14]. The experimental unfilled resin consisted of 78.4\% bisGMA, 19.6\% methylmethacrylate, 1.0\% 2-(dimethylamino) ethylmethacrylate and $1.0 \%( \pm)$-camphorquinone, blended together and prepared in polythene syringes, as previously described [8, 9, 13-15]. A sheet of commercially pure grade 2 Ti (Permascand, Ljungaverk, Sweden; >99\%) of 
Fig. 2 Silane (siloxane) film formation between silica-coated titanium and a resin matrix during silanization, using a blend of a functional silane and a cross-linking silane

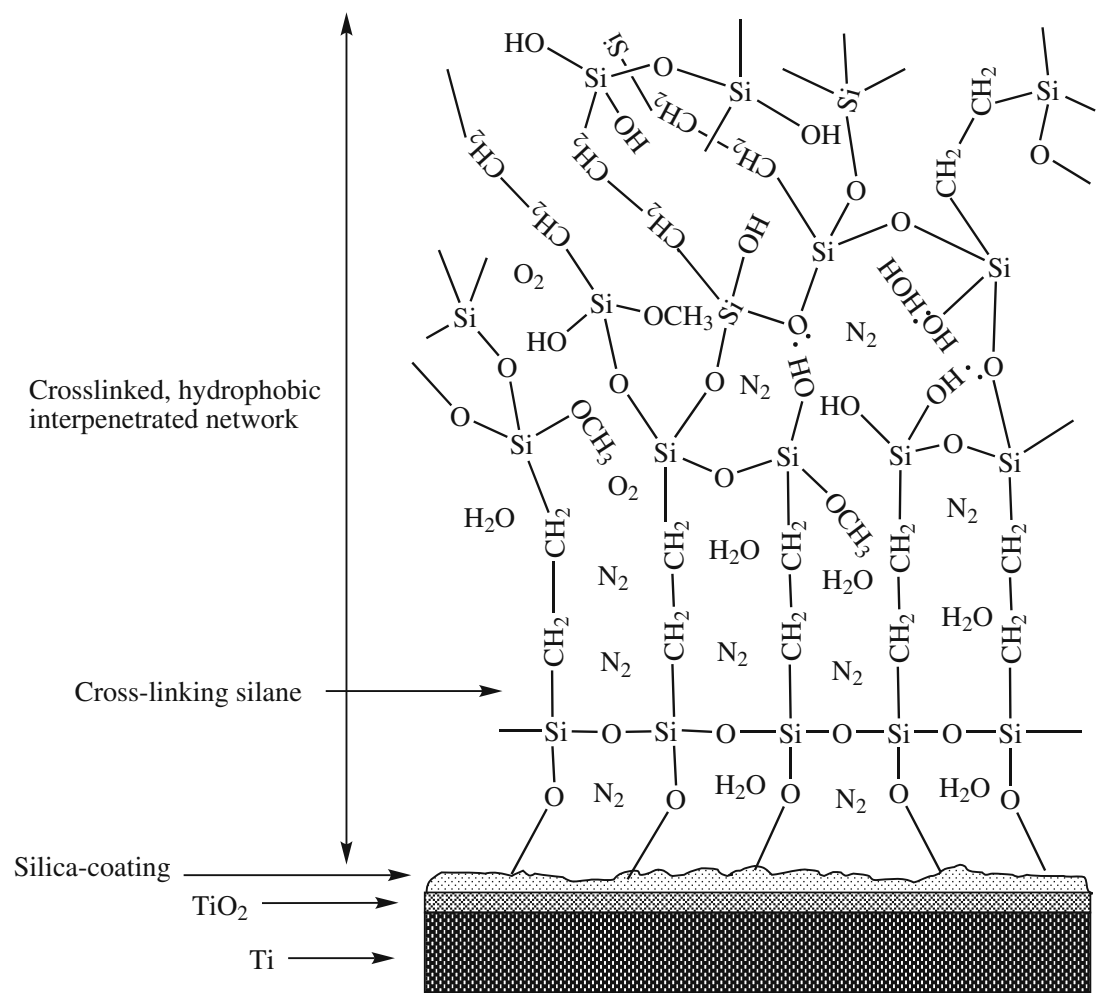

1-mm thickness was cut into coupons of $20 \mathrm{~mm}$ by $40 \mathrm{~mm}$ $(n=24)$. The upper half of the surface was grit-blasted with special silica-coated alumina sand (Rocatec ${ }^{\mathrm{TM}}$ system; ESPE, Seefeld, Germany), and the coupons were then cleaned ultrasonically.

Five experimental silane primers were prepared in $95 \%$ $(\mathrm{v} / \mathrm{v})$ ethanol in deionized water, and adjusted to $\mathrm{pH} 4.5$ with $1 \mathrm{M}$ acetic acid. First, a $1 \%$ solution of bis-1,2(triethoxysilyl)ethane was activated by hydrolysis for $23 \mathrm{~h}$ at room temperature; then the organofunctional silane was added to reach $1 \%$, and the blends were allowed to hydrolyze for an additional $1 \mathrm{~h}$ at room temperature [14]. A commercially available pre-activated silane product was used as the control [2].

The control and five primers were each applied onto 4 randomly selected silica-coated $\mathrm{Ti}$ coupons. The experimental resin was applied into polythene molds to form resin stubs with a diameter of $3.6 \mathrm{~mm}$ and a height of $4 \mathrm{~mm}$. Five resin stubs were evenly placed on the upper horizontal borders of each pretreated $\mathrm{Ti}$ coupon and the stubs were then photo-polymerized. The mold was then carefully removed [14-16]. Half of the specimens (2 coupons for each primer and control) were stored in deionized water for 6 months and half for 12 months in sealed polythene jars, kept in an incubator at a constant temperature of $37^{\circ} \mathrm{C}$.

Shear bond strength testing was performed with a universal material testing machine [16]. Tested specimens were examined by optical microscopy (50-100× magnifi- cation) and their failure mode was assessed: when $>66 \%$ remained on the $\mathrm{Ti}$ substrate, it was cohesive, when $>33 \%$ but $<66 \%$ remained, it was mixed failure and when $33 \%$ of the resin stub was left on the Ti surface, the failure type was adhesive.

Differences in shear bond strength were assessed with analysis of variance (ANOVA), using multiple comparisons; statistical significance was set at $p=0.001$ [14].

\section{Results and Discussion}

In this study we have assessed the in vitro effects of five experimental silane blends on resin-Ti adhesion after dry storage and two long-term water storage conditions. Longterm water storage in dental materials studies, e.g. for several weeks and several months (even years), is relevant to the clinical situation because dental materials are subject to continuous and constant humidity in the mouth. However, other physiological factors, such as biting forces and $\mathrm{pH}$ changes were beyond the scope of this study. The temperature was set at $37{ }^{\circ} \mathrm{C} \pm 1{ }^{\circ} \mathrm{C}$ to simulate the average oral temperature. Deionized water was selected as the storage medium since it is usually used in this type of experiment [8, 9, 11-15]. In some simulations, artificial saliva is used for the same purpose [17]. In general, the water sorption and solubility of resins (and resin-composites) are important issues and concerns in dentistry, because perma- 
Fig. 3 Shear bond strength values (in $\mathrm{MPa}$ ) after four different aging methods: dry storage ("Dry"), thermo-cycling ("TC6000"), 6 months of water storage, and 12 months of water storage. Abbreviations: ESPESil $=$ the control silane, TEXS = tetrakis-(2-methacryloxyethoxy)silane, BTSE = 1,2-bis-(triethoxysilyl)ethane, ACPS $=3$-acryloxypropyltrimethoxysilane, MPS=3-methacryloxypropyltrimethoxysilane, GPS=3-glycidoxypropyltrimethoxysilane, TSEF $=$ bis-[3-(triethoxysilyl)propyl]tetrasulfide

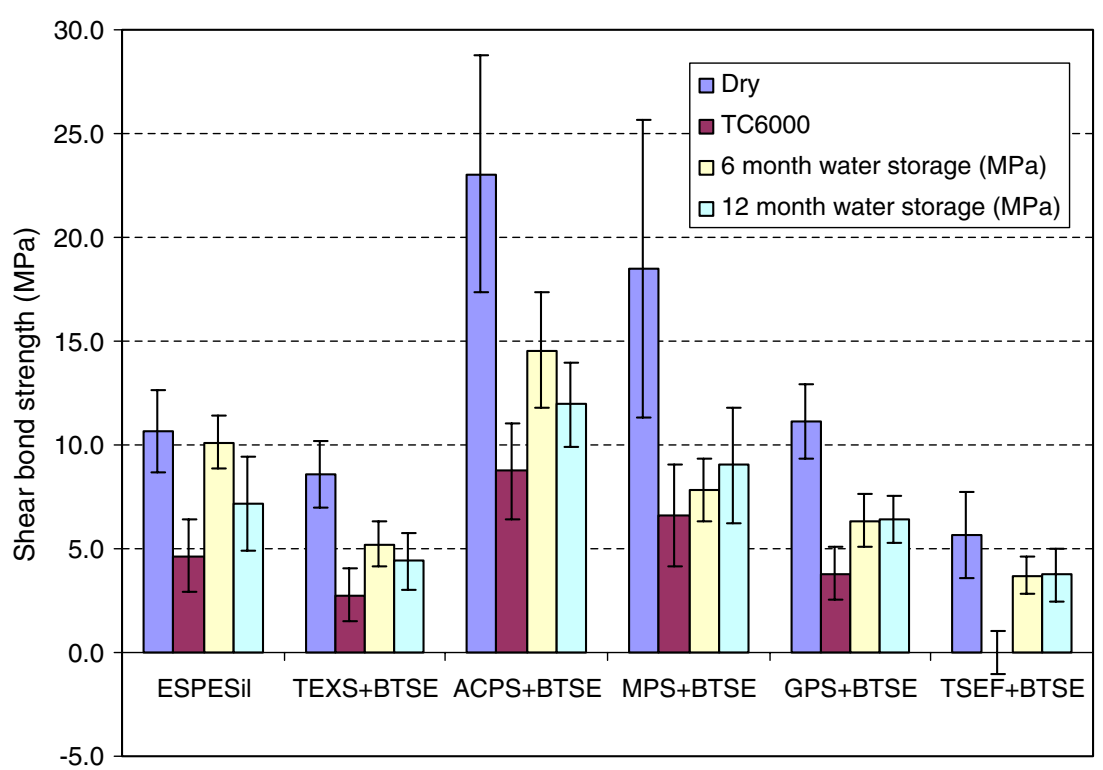

nent restorative materials and luting cements (resins) should have a long service time and they should not dissolve or degrade. The experimental resin type in this study has also been used in some of our previous studies [8, 14, 15, 18-20]. Its solubility and water-sorption properties have been reported recently [15]; hence in this study, we did not make observations about the solubility or sorption properties of the resin or the silica-coated surface.

Compared with the initial values, i.e. data obtained after dry storage, all the shear bond strength values after all artificial wet aging treatments were significantly lower, except for the control (Fig. 3, Tables 1 and 2). The shear bond strength values for the samples treated with control silane or each of the experimental silane primers was significantly higher after 6 and 12 months of water storage than after thermo-cycling. For the bis-[3-(triethoxysilyl) propyl]tetrasulfide + bis-1,2-(triethoxysilyl)ethane group, all thermo-cycled specimens underwent spontaneous debonding and had relatively low bonding values that were close to those for the tetrakis-(2-methacryloxyethoxy) silane + bis-1,2-(triethoxysilyl)ethane group. For 3acryloxypropyltrimethoxysilane + bis-1,2-(triethoxysilyl) ethane, with the highest initial shear bond strength value, a 6-month storage time significantly reduced the highest bonding values (Tables 1, 2, 3, 4 and 5).

It is not surprising that the failure mode analysis after water storage yielded relatively similar results to those achieved after thermo-cycling [14]: for 3-acryloxypropyltrimethoxysilane + bis-1,2-(triethoxysilyl)ethane, the failure mode was predominantly mixed, at $60 \%$, with $40 \%$ cohesive failure. The control group exhibited a predominantly cohesive failure mode, at $60 \%$, which is in concordance with the group treated with 3-methacryloxypropyltrimethoxysilane + bis-1,2-(triethoxysilyl)ethane which showed $50 \%$ cohesive and $50 \%$ mixed failure (Table 1). Thermo-cycling usually significantly lowers

Table 1 Mean shear bond strength (standard deviation [SD]) after 6 and 12 months of water storage and with the observed failure type $(n=10$ per group)

\begin{tabular}{|c|c|c|c|c|c|c|c|c|}
\hline \multirow[t]{2}{*}{ Silane type } & \multicolumn{4}{|l|}{ 6-month water storage } & \multicolumn{4}{|c|}{ 12-month water storage } \\
\hline & $\begin{array}{l}\text { Shear bond strength } \\
\text { (SD) }[\mathrm{MPa}]\end{array}$ & $\begin{array}{l}\text { Cohesive } \\
\text { failure [\%] }\end{array}$ & $\begin{array}{l}\text { Mixed } \\
\text { failure [\%] }\end{array}$ & $\begin{array}{l}\text { Adhesive } \\
\text { failure [\%] }\end{array}$ & $\begin{array}{l}\text { Shear bond strength } \\
\text { (SD) }[\mathrm{MPa}]\end{array}$ & $\begin{array}{l}\text { Cohesive } \\
\text { failure [\%] }\end{array}$ & $\begin{array}{l}\text { Mixed } \\
\text { failure [\%] }\end{array}$ & $\begin{array}{l}\text { Adhesive } \\
\text { failure [\%] }\end{array}$ \\
\hline Control ESPE Sil & $10.1(1.3)$ & 60 & 40 & 0 & $7.4(2.4)$ & 60 & 40 & 0 \\
\hline ACPS + BTSE & $14.6(2.9)$ & 40 & 60 & 0 & $12.0(2.1)$ & 40 & 60 & 0 \\
\hline $\mathrm{MPS}+\mathrm{BTSE}$ & $7.8(1.6)$ & 50 & 50 & 0 & $9.0(3.0)$ & 50 & 50 & 0 \\
\hline GPS + BTSE & $6.4(1.4)$ & 0 & 0 & 100 & $6.4(1.2)$ & 0 & 0 & 100 \\
\hline TEXS + BTSE & $5.2(1.1)$ & 0 & 0 & 100 & $4.4(1.4)$ & 0 & 0 & 100 \\
\hline TSEF + BTSE & $3.7(1.0)$ & 0 & 0 & 100 & $3.7(1.3)$ & 0 & 0 & 100 \\
\hline
\end{tabular}

Abbreviations: see Fig. 3 caption 
Table 2 Mean shear bond strength with standard deviation (SD), after all four storage types ( $n=10$ per group) [14]

\begin{tabular}{lllrl}
\hline Silane type & \multicolumn{4}{l}{ Shear bond strength (SD) [MPa] } \\
\cline { 2 - 5 } & Dry storage Ref. [14] & Thermo-cycling Ref. [14] & Water storage 6 months & Water storage 12 months \\
\hline Control ESPE Sil & $10.6(2.1)$ & $4.7(1.9)$ & $10.1(1.3)$ & $7.4(2.4)$ \\
ACPS + BTSE & $23.0(6.0)$ & $8.7(2.4)$ & $14.6(2.9)$ & $12.0(2.1)$ \\
MPS + BTSE & $20.0(6.3)$ & $6.6(2.6)$ & $7.8(1.6)$ & $9.0(3.0)$ \\
GPS + BTSE & $11.1(1.9)$ & $3.8(1.4)$ & $6.4(1.4)$ & $6.4(1.2)$ \\
TEXS + BTSE & $8.6(1.6)$ & $2.8(1.4)$ & $5.2(1.1)$ & $4.4(1.4)$ \\
TSEF + BTSE & $6.0(2.1)$ & $0.0(0.0)$ & $3.7(1.0)$ & $3.7(1.3)$ \\
\hline
\end{tabular}

Abbreviations: see Fig. 3 caption

shear bond strength values, as demonstrated in our previous study [18]. Adhesion promotion with 3-glycidoxypropyltrimethoxysilane, tetrakis-(2-methacryloxyethoxy)silane and bis-[3-(triethoxysilyl)propyl]tetrasulfide blended with bis-1,2-(triethoxysilyl)ethane exhibited failure solely at the adhesive interface, although no spontaneous debonding was observed for these groups. Nevertheless, these findings suggest that the bonding was not hydrolytically stable when these three silane blends were used to promote adhesion. Therefore, the bis-GMA/MMA resin system exhibits a chemical and/or molecular mismatch with these three experimental primers, such that the primers may have somehow modified the silica-coated Ti surface.

Our statistical analyses (Tables 3, 4 and 5), which included data from our previous publication [14], revealed that the type of functional silane $(p<0.001)$ and storage conditions $(p<0.001)$ significantly affected the shear bond strength. Acrylate and methacrylate are the most reactive functionalities for silane coupling agents [2-4, 21, 23, 24]. Their blends with the cross-linking silane produced the highest bonding values, compared with values for the control group and the groups using the other three experimental primers. Compared with the control silane, use of 3-methacryloxypropyltrimethoxysilane + bis-1,2(triethoxysilyl)ethane led to a change in bonding strength of $+22 \%$ after 12 months of water storage and, perhaps surprisingly, $-23 \%$ after 6 months of water storage, which is not easy to explain. For 3-acryloxypropyltrimethoxysilane + bis-1,2-(triethoxysilyl)ethane, the change was $+62 \%$ after 12 months and $+44 \%$ after 6 months. Finally, the control and the primers 3-acryloxypropyltrimethoxysilane, 3-methacryloxypropyltrimethoxysilane, and 3-glycidoxypropyltrimethoxysilane blended with bis-1,2(triethoxysilyl)ethane produced under 12 months of water storage shear bond strength values that exceeded the formal minimum threshold of $5 \mathrm{MPa}$, which is set for prosthodontic materials [16].

In principle, van der Waals forces are strong enough to account for durable bonding between solid material substrates and polymers if the contact is extremely intimate [21]. Perfect contact between the substrate and polymer should lead to bonding so strong that the failure mode should be in the polymer or substrate, which represents cohesive failure. It has been proposed that failures in adhesion are due to the weak boundary layer at the interface [22]. Nevertheless, in practice, surfaces are always rough rather than smooth, and intimate contact between the substrate and resin is virtually impossible.

Silica and silica-coated surfaces are polar and hydrophilic, which makes them prone to spontaneous water adsorption. Accordingly, dilute solutions of activated (hydrolyzed) silanes wet a substrate effectively and displace
Table 3 Statistical analysis of data from this and a previous study [14] using tests of between-subject effects (two-way ANOVA) for the shear bond strength of the experimental silane primers

a. $\mathrm{R}$ squared $=0.864$ (adjusted $\mathrm{R}$ squared $=0.849$ )

\begin{tabular}{lcrrrr}
\hline Source & Sum of squares & df & Mean square & F & p level \\
\hline Corrected model & 13243.801 a & 26 & 509.377 & 56.625 & 0.000 \\
Intercept & 26046.745 & 1 & 26046.745 & 2895.478 & 0.000 \\
Silane & 7728.802 & 6 & 1288.134 & 143.195 & 0.000 \\
Storage time & 3080.991 & 3 & 1026.997 & 114.166 & 0.000 \\
Silane * Storage time & 1610.356 & 17 & 94.727 & 10.530 & 0.000 \\
Error & 2086.994 & 232 & 8.996 & & \\
Total & 41943.861 & 259 & & & \\
Corrected total & 15330.795 & 258 & & & \\
\hline
\end{tabular}


Table 4 Statistical analysis of data from this and a previous study [14] using multiple comparisons (Tukey HSD) for the shear bond strength of the experimental silane primers, based on observed means

Abbreviations: see Fig. 3 caption

\begin{tabular}{lllll}
\hline Silane (I) & Silane (J) & Mean difference (I-J) & Standard error & $p$ value \\
\hline Control & ACPS + BTSE & -6.022 & 0.6584 & 0.000 \\
& MPS + BTSE & -2.156 & 0.6532 & 0.019 \\
& GPS + BTSE & 1.281 & 0.6532 & 0.443 \\
& TEXS + BTSE & 3.011 & 0.6483 & 0.000 \\
& TSEF + BTSE & 4.257 & 0.6817 & 0.000 \\
\hline
\end{tabular}

air from its surface, without having to be $100 \%$ hydrolyzed $[3,6,7]$. Silane coupling agents exhibit strong adhesion to clean metal, metal oxide, glass surfaces and, in particular, silica surfaces. In general, in reinforced plastics such as resin composites, the silica or glass filler particles are always silanized to maintain their adhesion to the hydrophobic polymer matrix [1-4]. The methacrylate functional silane, 3-methacryloxypropyltrimethoxysilane, is well known as one of the most effective silane coupling agents for bonding glass to polyesters when applied as a dilute solution, e.g. $0.5 \%-2.0 \%$ in water-alcohol blends [23]. It is necessary to emphasize that any silane deposited on a surface should not be considered as an adhesive per se, but rather as a means of providing a hydrolytically stable, primed surface of controlled polarity to which the monomers of a resin adhere.

Adhesion of polymers to dissimilar substrates involves a dynamic equilibrium of creating and breaking of adhesion bonds [24]. In addition, resin composites undergo polymerization shrinkage and controlling the filler size and load is one way of minimizing volumetric changes [25]. Ti, the silica-coating layer and the experimental resin have obviously different coefficients of thermal expansion, although these were not measured in this study. On the other hand, the temperature was kept constant. Stresses, such as those in polymerization shrinkage, are not dispersed uniformly in the experimental bis-GMA/MMA resin mass. These stresses can initiate cracks in the resin and at certain points in the interface. Therefore, we cannot avoid shrinkage stresses between most mineral surfaces such as those in silica-coated metals and polymers.

Owing to its relatively small size, ambient water can penetrate the resin stub to reach the silica-coated Ti surface (cf. Fig. 2). The suggested mechanism [4, 24] is based on capillary migration or filtering through cracks. In other words, water cannot be excluded from the interface between the experimental resin and the substrate. The hydrolytic intrusion of water may also cause a self-healing effect, so that stresses can relax without disrupting the silane-film aided bonding. The reaction is reversible because silanes with silanol groups, $\equiv \mathrm{Si}-\mathrm{OH}$, can uniquely compete with water on the substrate surface [3-6]. In the siloxane film, the reversible breaking and re-making of bonds, both of hydrogen bonds and of covalent bonds, occurs through stress deterioration. The latter is promoted by the presence of water at the interface, which supposedly imparts ductility to the experimental bis-GMA/MMA resin, in a similar way to how slippage of atom planes at the silica-Ti-surface imparts ductility to $\mathrm{Ti}$ and its silica-coating [21-24].

In the first study in our series [14], we discussed the shear bond strength testing and thermo-cycling as an aging method. The authors' opinion is that these testing methods can, and should, be employed in dental materials studies, although it should be borne in mind that they have limitations and that the adhesion results obtained need to be observed critically [26-28].

\section{Conclusions}

In this second part of our in vitro study we have evaluated the adhesion promotion effect of five different experimental primers on a silica-coated $\mathrm{Ti}$ surface after two long-term wet storage types, 6 months and 12 months at $37^{\circ} \mathrm{C}$. Five functional activated silane monomers were blended with a cross-linking silane. After long-term water storage, the shear bond strength values obtained in the 3acryloxypropyltrimethoxysilane + bis-1,2-(triethoxysilyl) ethane group were the highest among all groups. The study hypothesis was partially proven and significant differences were observed between shear bond strength values obtained with the different experimental primers.

Table 5 Statistical analysis of data from this and a previous study [14] using multiple comparisons (Scheffe's test) versus the control silane for the shear bond strength of the experimental silane primers, based on observed means

\begin{tabular}{lcc}
\hline Silane & \multicolumn{2}{c}{$95 \%$ confidence interval } \\
\cline { 2 - 3 } & Lower limit & Upper limit \\
\hline ACPS + BTSE & -8.380 & -3.664 \\
MPS + BTSE & -4.495 & 0.184 \\
GPS + BTSE & -1.059 & 3.620 \\
TEXS + BTSE & 0.689 & 5.332 \\
TSEF + BTSE & 1.816 & 6.699 \\
\hline
\end{tabular}

Abbreviations: see Fig. 3 caption 
Acknowledgements We thank Dr. Barry Arkles (Gelest Inc., Tullytown, PA, USA) for donating the silane monomers for our study and Dr. Trevor Lane (The University of Hong Kong) for proofreading the manuscript.

Open Access This article is distributed under the terms of the Creative Commons Attribution Noncommercial License which permits any noncommercial use, distribution, and reproduction in any medium, provided the original author(s) and source are credited.

\section{References}

1. Meiners H, Herrmann R, Spitzbarth S (1990) Dent-Labor 38:185

2. Matinlinna J, Lassila LVJ, Özcan M, Yli-Urpo A, Vallittu PK (2004) Int J Prosthodont 17:155

3. Rosen MR (1978) J Coat Technol 50:70

4. Plueddemann EP (1982) Silane coupling agents. Plenum, New York

5. Sundararajan PG, van Ooij WJ (2000) Surf Eng 16:315

6. van Ooij WJ, Zhu DQ, Prasad G, Jayaseelan S, Fu Y, Teredesai N (2000) Surf Eng 16:386

7. Klempner D, Sperling LH, Utracki LA (1994) Interpenetrating polymer network. Advances in chemical sciences. Am Chem Soc, Washington, Vol. 239

8. Matinlinna JP, Lassila LVJ, Vallittu PK (2007) Dent Mater 23:1173

9. Matinlinna JP, Lassila LVJ, Vallittu PK (2007) Acta Odontol Scand 65:44

10. Bowen RL, Marjenhoff WA (1992) Adv Dent Res 6:44
11. Kern M, Thompson VP (1994) J Dent 22:300

12. Kern M, Thompson VP (1995) J Prosthodont 4:16

13. Matinlinna JP, Lassila LVJ, Kangasniemi I, Yli-Urpo A, Vallittu PK (2005) Dent Mater 21:287

14. Matinlinna JP, Lassila LV, Vallittu PK (2010) Experimental novel silane system in adhesion promotion between dental resin and pretreated titanium. Silicon 1:249-254

15. Puska M, Lassila L, Seppälä J, Vallittu P, Matinlinna J (2009) J Adhes Sci Technol 23:991

16. International Organization for Standardization (ISO) (1996) Dentistry-polymer-based crown and bridge materials, Amendment 1996; ISO 10477

17. Darvell BW (1978) J Oral Rehabil 5:41

18. Matinlinna JP, Lassila LVJ, Vallittu PK (2006) J Dent 34:740

19. Matinlinna JP, Dahl JE, Lassila LVJ, Vallittu PK (2007) In: Mittal KL (ed) Silanes and other coupling agents, vol. 4. pp 8397

20. Matinlinna JP, Lassila LVJ, Kangasniemi I, Vallittu PK (2005) J Dent Res 84:360

21. Plueddemann EP (1968) J Paint Technol 40:1

22. Bikerman JJ (1967) Ind Eng Chem 59:41

23. Plueddemann EP (1962) Mod Plast 39:135

24. Plueddemann EP (1970) Mod Plast 47:92

25. van Noort R (2007) Introduction to dental materials, 3rd edn. Mosby Elsevier, Edinburgh

26. Matinlinna JP, Mittal KL (eds) (2009) Adhesion aspects in dentistry. VSP/Brill, Leiden

27. Söderholm K-J (2009) J Adhes Sci Technol 23:973

28. Darvell BW (2009) J Adhes Sci Technol 23:935 